This item was submitted to Loughborough's Research Repository by the author.

Items in Figshare are protected by copyright, with all rights reserved, unless otherwise indicated.

\title{
Responses to the vision zero articles
}

PLEASE CITE THE PUBLISHED VERSION

https://doi.org/10.1080/14773996.2017.1361110

\section{PUBLISHER}

Taylor \& Francis @ Institution of Occupational Safety and Health

\section{VERSION}

AM (Accepted Manuscript)

\section{PUBLISHER STATEMENT}

This work is made available according to the conditions of the Creative Commons Attribution-NonCommercialNoDerivatives 4.0 International (CC BY-NC-ND 4.0) licence. Full details of this licence are available at: https://creativecommons.org/licenses/by-nc-nd/4.0/

\section{LICENCE}

CC BY-NC-ND 4.0

\section{REPOSITORY RECORD}

Sherratt, F., and Andrew Dainty. 2019. "Responses to the Vision Zero Articles". figshare. https://hdl.handle.net/2134/37072. 


\title{
Responses to the Vision Zero Articles
}

\author{
Fred Sherratt ${ }^{1}$ and Andrew R. J. Dainty ${ }^{2}$ \\ ${ }^{1}$ Department of Engineering and the Built Environment, Anglia Ruskin University, Chelmsford, UK \\ ${ }^{2}$ School of Civil and Building Engineering, Loughborough University, Loughborough, UK
}

Vision Zero: from accident prevention to the promotion of health, safety and well-being at work

\section{Zwetsloot, Stavroula and Kines}

Zwetsloot et al have long been champions of the Zero Accident Vision (ZAV), vocal in their rebuttal of various critiques of its influence on safety management and keen to promote and support its implementation in practice. Within this this paper they remain firm to their foundational beliefs: firstly that '...all accidents are preventable' (p2) and secondly, that ZAV is a 'journey' (p2), a path to follow towards 'safety excellence' (p2), rather than any ultimate goal. The latter argument is often used in the defence of the ZAV, as it is again in this paper, positioned as a basic 'misunderstanding' by those who critique it. Yet these two points of origin, when taken together, raise what could be considered the fundamental challenge to the ZAV: why does the former not inevitably direct the latter towards a goal of zero accidents? Why must perceptions be redirected away from this goal for ZAV to be effective? Why can we not look to a target of zero if all accidents can be prevented? If Zero is not to be positioned as such, what is it doing in the title of the 'Vision' itself, being the numerical quantification it inevitably is? It must be recognised that interpretation is a critical aspect of any Health and Safety at work intervention, so to argue that the ZAV has been misunderstood, and furthermore to even suggest that it can so easily be misunderstood, does not reassure us of its effectiveness in practice or the relevance of the safety discourse it inevitably promotes. Thus, a key question remains: why not simply rebrand as 'Innovative Safety', or similar, and avoid the debates of logical semantics at one level, and irrelevance to practice at another? Although Zwetsloot et al remain firm in their continued adherence to Zero, with the ZAV here supplemented by Vision Zero (VZ) and Zero Harm (ZH), we suggest that the positioning of Zero in the forefront of advances in health, safety and wellbeing management in practice is becoming ever more challenged. More troublingly, ZAV runs the risk of being labelled as safety propaganda, which distracts and misdirects from the essential business of keeping people safe and health and well at work. Taken to its natural conclusion, the ZAV effectively becoming a self-defeating discourse.

Indeed, the relevance and leadership of the ZAV can be disputed through the empirical work of Young (2014) which despite its promotion as a ZAV success story instead challenges many of its basic tenets, focusing specifically on the goal of zero and attained through 'persistence with hierarchy of control methodology' (2014:106) rather than any 'innovative' approaches to safety. Furthermore, Zwetsloot et al's inclusion of 'associated concepts and theories' to support the ZAV 'innovative perspectives' also suggests the relevance of the ZAV in practice is waning; worker empowerment is not itself innovative but a core aspect of adaptive safety, duly acknowledged with reference to resilience engineering, but what the ZAV adds to this established safety management approach remains unclear.

The ZAV, rebranded as ZH for worker health, safety and wellbeing, has become ever more disassociated from practice; directed very much to the corporate level and so bringing with it the lexicon of corporate management speak. Talk of 'mindsets', and 'commitment strategies' and 'leadership' abound, but with little recognition of what they could or should actually look like in real 
life, or what changes and improvements they could or should bring to the workspace. The consideration of worker health and well-being as of equal importance to safety is certainly to be welcomed, and several highly relevant aspects are noted here including stress, fatigue and the consequences of globalisation, but the 'innovative perspectives' presented lack specificity in terms of their implementation. They arguably do not add to practice themselves, but instead go some way to explain why the ZAV is still a growing safety phenomena, able as it is to provide much needed content for corporate PR and the development of a 'Brand Zero'.

Throughout this paper, Zwetsloot et al present a ZAV that seems disconnected from the realities and lived experiences of work. The adoption of a ZAV/ZH has instead become a relatively easy addition to the corporate profile, with little real change actually required in practice. Although it is easy to consider the academic fuss around the ZAV to be an exercise in logical semantics, discourse or philosophy, the positive impacts of a ZAV lack empirical support. Until there is demonstrable evidence that a ZAV can be operationalised in a way that works for the workers, there is also the need for a strong counter-discourse to challenge and critique. We argue that until it is clear that ZAV does not lead to unintended negative consequences for accident reporting, learning and worker engagement with HSW innovations, a more cautious approach is appropriate. Until it can be empirically established that safety is working because of and not in spite of zero, it should not be held up as the way forwards. Indeed, the reference here of 'associated concepts and theories', such as adaptive safety, already acknowledges that there are other practical and innovative efforts being made elsewhere, which make no mention of Zero, in any form, at all.

\section{References}

Young, S. (2014). From zero to hero. A case study of industrial injury reduction: New Zealand Aluminium Smelters Limited. Safety Science. 64, 99-108.

http://dx.doi.org/10.1016/j.ssci.2013.11.016 


\section{Zero Vision: enlightenment and new religion}

Dekker

Dekker has been a vocal critic of Zero and ZAV since its emergence within the field of safety management, and in this paper he draws on two key strands to reinforce this stance. From a practical position, Dekker again argues that the empirical evidence for a ZAV is lacking, and the continuing inability to extract Zero as a specific variable within many research projects simply serves to obfuscate its actual role and influence on any safety management practices. Such a critique is more focused than some, and adds a specific facet to the counter-discourse to the ZAV. The other, perhaps more significant contribution made by this paper is the reframing of context not just for ZAV but for health, safety and wellbeing management overall, and the mobilisation of this to develop both a more nuanced critique of zero and the presentation of an alternative vision for the future.

Culturally, we all too frequently live in ahistorical times, and the desires that underlie health and safety management often go unremarked, shrouded in unchallenged notions of ethics or corporate social responsibility. In looking backwards and taking a historical perspective, Dekker therefore enables us to better understand why we are where we are, and brings a welcome anomaly to the wider discourse of HSW management thinking. It remains vitally important that we are able to acknowledge and understand our foundations which, as Dekker argues, can also help us find a better path to the future; one that works and finds fit with our current social world. In this paper, human progress as traced through Religion (specifically Christianity in the West), the Enlightenment and Secularisation that came with the growth in science and rationality, are shown to have contributed to and culminated in the positioning of Zero on its safety management pedestal. Yet this position is untenable in our world, as demonstrated by plateauing safety performance, and the perhaps inevitable focus on controlling deviation, bureaucratisation and counting down to zero have all been shown to be ineffective. But as Dekker clearly points out, this enhanced understanding also allows us to recognise the alleviation of suffering as a practical yet still ethical approach to safety management, reframing our understandings of why and what we are aiming to achieve, seeking positives rather than negatives in practice, without the need for zero to hold any influence at all. 